\title{
Dilemas da cooperação: conflitos gerados pela política das "Listas Negras" no Brasil durante a Segunda Guerra Mundial
}

Dilemmas of cooperation: the conflicts provoked by the policy of "Black Lists" in Brazil during World War II

TANIA QUINTANEIRO*

Rev. Bras. Polít. Int. 49 (2): 78-98 [2005]

\section{Introdução}

As "Listas Negras"ofereceram, durante a Segunda Guerra, sustentação coercitiva à expansão e consolidação da hegemonia dos Estados Unidos na América Latina. ${ }^{1}$ Estruturadas a partir de necessidades impostas pelo conflito bélico e dos objetivos econômicos e políticos norte-americanos, elas incidiram na economia e na soberania dos países onde foram aplicadas e permitiram aperfeiçoar métodos para identificar, bloquear e eliminar empresas controladas por nacionais de países do Eixo que atuavam no continente ou por seus representantes. Com a justificativa do combate global ao totalitarismo, a intervenção em firmas "indesejáveis" e a substituição de sócios e empregados propiciou a abertura de um amplo espaço de oportunidades a ser repartido entre os Aliados.

Este trabalho identifica os fundamentos e a trajetória dessa política, os pontos de fricção criados no interior do aparelho de estado norte-americano, os conflitos gerados na sua implantação no Brasil, tanto com a Grã Bretanha, como com o governo Vargas, que buscava paliar os efeitos negativos de tais medidas sobre a economia nacional e, ao mesmo tempo, cooperar no chamado "esforço bélico" junto aos Estados Unidos, de modo a garantir insumos essenciais para o desenvolvimento industrial do país.

\footnotetext{
* Professora do Departamento de Sociologia e Antropologia da Universidade Federal de Minas Gerais UFMG (taniaq@terra.com.br).

${ }^{1}$ Uma bolsa da FAPEMIG possibilitou a pesquisa de documentos do Departamento de Estado, da embaixada e consulados no Brasil, de enviados especiais e órgãos executivos nos National Archives and Records Administration.
} 


\section{A operacionalização das "Lista"s: os desafios da ação coletiva}

A bem-sucedida coação econômica, praticada pela Grã Bretanha na Primeira Guerra Mundial através da Statutory List ou SL e da Black List e rediviva em 40, foi potencializada quando, em 17 de julho de 41, Roosevelt somou-se à estratégia, ordenando que os secretários de Estado, Tesouro e Comércio, o procurador-geral, o administrador dos Controles de Exportação e o coordenador de Assuntos Interamericanos preparassem uma relação de indivíduos e empresas conectados a pessoas e naçóes do Eixo, a serem bloqueados em nome dos interesses da defesa nacional: a Proclaimed List of Blocked Nationals ou PL, popularmente "Lista Negra". ${ }^{2}$ Até sua extinção, em julho de 46, a "Lista" e seus arquivos foram administrados pela World Trade Intelligence, enquanto as embaixadas abrigavam os comitês interdepartamentais. Pretendia-se debilitar a economia das potências inimigas, desorganizando as redes de distribuição de seus produtos e cortando o abastecimento de sua indústria. Para fechar o cerco, proibiram-se as companhias estadunidenses de negociar com os bloqueados e tê-los como representantes. Se transgredissem, eram acusadas de violar a ordem de congelamento. Esta exigia, de nativos e firmas de países inimigos, licença do Tesouro, concedida por curtos períodos caso afastada qualquer suspeita de favorecimento ao Eixo. Renová-la demandava relatórios detalhados, podendo ser exigidas demissões e a reorganização da empresa. Refinava-se o esforço de racionalização da burocracia norte-americana, cujo dilema era assegurar a eficácia do controle sem prejudicar os seus nacionais.

A denominação "empresas totalitárias", criada com claro apelo ideológico, foi aplicada aos estabelecimentos "total ou parcialmente alemães, italianos, russos ou espanhóis em pessoal, propriedade ou controle, e antiamericanos em simpatia, ou que se engajam em atividade inimiga dos interesses de alguma ou de todas as repúblicas americanas". ${ }^{3}$ Elas se classificavam em: incluídas na PL; sujeitas a liquidação; submetidas a reorganização e supervisão; e a serem fiscalizadas pelas autoridades nacionais dado seu menor destaque e risco. $\mathrm{Na}$ aquilatação de quais eram as firmas "de tamanho e importância suficientes para exigir ação específica por parte das autoridades no Brasil,", existia certa dose de arbítrio. ${ }^{4}$ Quando deviam ser reorganizadas e supervisionadas, por meio da atuação do governo local, este eventualmente era mais severo do que o comitê, de modo a conservar uma parcela de decisão, útil na hora de proteger interesses ou indicar compradores "satisfatórios" para empresas desvalorizadas pelo estigma da PL.

\footnotetext{
${ }^{2}$ http://www.ushmm.org/uia-cgi/uia_doc/art/x10-37?hr=null.

3 Department of State 7.2.1941.

4 Tewell 30.11.1943.
} 
A implantação do bloqueio originou atritos e problemas de coordenação entre órgãos do Estado norte-americano. A "lei de ferro" das oligarquias materializava-se à proporção que agências criadas nas circunstâncias da guerra tentavam ampliar seu espaço político e garantir seu quinhão de poder, promovendo padrões próprios de seleção. Novas listas desabrocharam e vigoraram por mais ou menos tempo, num cipoal de denominaçóes e apelidos: a Black List para pessoas físicas, a Watch List, para censura e eventuais erros de retirada de uns e captura de outros que, sentindo-se confiantes, viessem a se expor. A mais duradoura, a Confidential List of Unsatisfactory Consignees (CL, CLUC ou Grey List), servia de base à concessão de licenças para a exportação e importação de materiais estratégicos ou escassos. Os que obtinham os "certificados de preferência" deviam ser bem estabelecidos, confiáveis, cooperadores com os programas de guerra econômica, não terem como fim explorar a oferta insuficiente de produtos, e evitar escrupulosamente negociar com bloqueados. ${ }^{5}$ Uma das tarefas da CL era prevenir a fundação, por testasde-ferro, de empresas para estocar e repassar, aos bloqueados, produtos oriundos dos Estados Unidos. Suspeitos de fornecimento ou que, por negligência ou intencionalmente, especulassem com a escassez eram recomendados para a CL e, se necessário e politicamente viável, transferidos para a PL. As autoridades norte-americanas reconheciam que o ardil dos indiciados para reaparecer prontamente nos negócios, sob nova feição, era maior do que a capacidade de seu sistema para identificá-los e acrescentá-los ao grupo daqueles "cujas operaçóes foram suficientemente bem estabelecidas". ${ }^{6}$ Alguns critérios de indicação para a CL eram propositalmente imprecisos, identificando preventivamente quem se conectasse a firmas "em relação às quais exista informação adversa de natureza política, ou de algum relacionamento com firmas da PL, ou suspeitas definidas", como nacionalidade ou nascimento, simpatias ou relaçóes com instituiçóes e governos inimigos. ${ }^{7}$

O Departamento de Estado temia que a CL interferisse no alcance dos fins da PL, especialmente se ocorrências importantes passassem à sua alçada, ligando o alarme para que outras agências inventassem novas listas. Conjugar rapidez e confiabilidade na fiscalização era um dilema que se complicava na medida que tais iniciativas dificultavam a coordenação e estimulavam atritos entre as instâncias burocráticas. Por outro lado, o caráter confidencial da CL se extinguia quando aqueles que tivessem as licenças recusadas se queixassem a seus governos. Uma profusão de controles velados paralisaria o comércio, deixando confusas as casas comerciais dos Estados Unidos num momento em que havia excesso de pedidos domésticos e que o governo dizia-se quase "forçado

\footnotetext{
5 Department of State 7.12.1942.

${ }^{6}$ Caffery 26.11.1941.

7 Department of State 7.12.1942.
} 
a implorar às empresas para manterem negócios essenciais com as repúblicas americanas". ${ }^{8}$ Para ser eficaz, a CL tinha que ser "colocada em mãos de ao menos seis departamentos, todos os agentes alfandegários, todos os Federal Reserve Banks, todos os grandes bancos que fazem negócios no exterior, todas as missões diplomáticas e consulados nos países afetados, grandes firmas dos Estados Unidos nos países afetados, agências e missóes governamentais britânicas e canadenses", ${ }^{9}$ inviabilizando seu sigilo. A CL poderia tornar-se aceitável e valiosa "como um controle suplementar, mais do que alternativo, da PL", menos adequada para vigiar indivíduos.

Quando demandas da guerra econômica levaram a que a CL fosse confiada aos comitês da PL, uma comissão considerou abolir as licenças a empresas não bloqueadas, monitorar todas as mercadorias que saíam de portos estadunidenses, e conceder licenças temporárias para produtos sujeitos a critérios menos rigorosos ou para quantidades limitadas, abrandando a norma de negá-las automaticamente aos listados na CL. Havia que frear o incremento das operações burocráticas e reduzir pontos de obstrução.

Empresas estadunidenses nada interessadas na substituição de representantes ou na suspensão de seus negócios na região cobravam tolerância, que dependia, em parte, da extensão de seus interesses. Se fatores políticos assim o aconselhassem, havia que considerar exceçôes, mais prementes se o bloqueio colocasse em risco a economia do país, cabendo ao governo nacional papel ativo nessa definição. Ainda assim, o controle e a eliminação de negócios era possível "se a questão fosse discretamente tratada". O comitê incluía e retirava nomes, investigava, entrevistava, licenciava, verificava publicações oficiais e na imprensa e correspondências interceptadas, controlava consignatários e empregados, negociava com funcionários brasileiros e liquidantes, e preparava relatórios. ${ }^{10} \mathrm{Em}$ decorrência da dimensão do território brasileiro e das deficiências de transportes e comunicaçôes, o sortimento dos problemas era vasto, e as soluções úteis em outros episódios. O comitê da PL ressentia-se com a morosidade e a precariedade na obtenção de dados confiáveis, mas, por outro lado, era acusado de agir injusta e precipitadamente ao incluir suspeitos sem ter checado as provas. Para contornar tais contratempos, criou quatro níveis de confiabilidade dos dados.

As fichas registram sistematicamente os dados das empresas: origem nacional, mudanças de nome, capital, fundação, ramo de atividade, representados, importância econômica, referências, percentual de compras no exterior por país, participação em Câmaras de Comércio e até o idioma preferido em sua correspondência. Sobre os proprietários, indicam entrada, saída,

\footnotetext{
${ }^{8}$ Donnelly 13.11 .1942$.

9 Acheson 30.3.1942.

10 American Embassy 16.12.1942.
} 
sucessão e substituição, nacionalidade, presença e classificação em outras listas e percentual de capital. Por vezes o conteúdo vago - "não se acredita que seja", "dizem que é" - não parece obedecer a qualquer critério que não o mero acúmulo de informações para futuros usos. A coleta e classificação desses materiais constituíram bancos de dados de importância fundamental no desenho de estratégias de expansão industrial e comercial estadunidenses, e eram, com freqüência, mais sofisticados e completos que os manejados pelo Estado brasileiro.

Os Estados Unidos visavam a desalojar a Alemanha dos mercados do continente mas, ao mesmo tempo, manter à distância o aliado e concorrente mais próximo. Isso colocou em rota de colisão britânicos e norte-americanos, que às vezes se consultavam na confecção das respectivas listas. Um de seus desacordos referia-se à negociação com as forças locais. Para reduzir pressões, a embaixada britânica se eximia do problema, transmitindo "a impressão de que não fora autorizada nem a discutir nem a determinar casos, e que agia segundo instruçōes do Ministry of Economic Warfare" ${ }^{11}$ No teatro da ação bélica, a Inglaterra estava em desvantagem para lidar com as repúblicas sul-americanas, dependendo politicamente dos Estados Unidos, e a redução de seu comércio deixava-as menos sensíveis à SL. Os britânicos sugeriram aos estadunidenses que adotassem "uma prática uniforme para lidar com perguntas, vindas seja do governo ou de indivíduos", com base no princípio de não dar, a ninguém, qualquer explicação sobre as razões de sua inclusão. ${ }^{12}$ Isto visava a impedir pressões locais que se tornariam insuportáveis se cada inserção na SL viesse a ser negociada, e dificultaria a identificação das estratégias a seguir para evitar o indiciamento. Paradoxalmente, seu rígido sistema podia alentar práticas de corrupção, como no episódio de uma pequena companhia, removida da SL mediante o pagamento de $£ 3.000$, e de mais $£ 1.500$ por parte de seu principal sócio, mesmo assim proibido de entrar em seu escritório por seis meses sob pena de multa, a não ser com permissão do consulado. ${ }^{13} \mathrm{O}$ Ministry of Economic Warfare acabou propondo, sem rodeios, "acrescentar à SL todos os casos que aparecessem na PL e qualquer acréscimo subseqüente à PL sem esperar pela completa apresentação da informação que resultou nesses casos", ainda que o Departamento de Estado e o comitê da PL não pretendessem adotar política similar. ${ }^{14}$

Contrariamente a isso, o embaixador norte-americano repetia o clichê de que pretendia "discutir todos os casos abertamente com as companhias que estavam sob consideração para inclusão ou com quem estava requerendo ser retirado da 'Lista'". Embora aceitasse cooperação, desaconselhava declarações

11 Caffery 1.4.1942.

12 British Embassy 11.8.1941.

13 Simmons 21.3.1942.

14 Acheson 25.11.1941. 
públicas a respeito a fim de não piorar a situação do ministro de Relações Exteriores, premido pelos empresários e "atormentado por firmas na 'Lista' e pelos seus amigos influentes". No estilo particularista da elite brasileira, "cada pessoa que é atingida pela PL ou tem amigos nela ataca Aranha”. ${ }^{15}$ Os Estados Unidos afirmavam ter "objetivos econômicos e militares" a atingir no Brasil, o que tornava crucial evitar ressentimentos, e dispunha-se a "retirar empresas da PL de maneira oportunista", ${ }^{16}$ desde que houvesse garantias de alcance dos fins por outras vias. A conduta adotada dependia de avaliação do impacto político. Apesar da imagem de flexíveis e democráticos, nem sempre essa orientação prevalecia. Sendo já o maior fornecedor de bens para o Brasil, as objeçôes oficiais e privadas brasileiras eram muito mais agudas. Mesmo os indiferentes à SL pressionavam para sair da PL. Pedidos particulares de remoção entupiam os canais diplomáticos. Gradativamente, os Estados Unidos adquiriam preeminência no controle, e a Inglaterra era obrigada a retrair-se.

\section{Cabo-de-guerra}

A estimativa inicial da PL no Brasil era de 6.000 cópias, com cerca de dez páginas cada, suplementadas, a cada três semanas, por mais duas. Previa-se que a relação dos que a receberiam pelo correio viesse em poucos meses a conter vários milhares de nomes. ${ }^{17} \mathrm{~A}$ revisão geral logo se reduziu de quatro a três meses. Com a prática das interdições, Aranha confirmou seu prognóstico de que, dentre suas conseqüências lamentáveis, estaria "a tentativa de substituir firmas genuinamente brasileiras por inglesas ou norte-americanas nãoespecializadas". Um exemplo foi a indicação da Wilson \& Sons, que nunca antes se ocupara da exportação de couros, para o lugar de estabelecimentos gaúchos que estavam no negócio havia mais de cem anos, e que "com ou sem razão foram incluídos na 'Lista". ${ }^{18} \mathrm{O}$ embaixador prometeu reconsiderar o caso, enquanto vaticinava que o ministro continuaria "a fazer comentários desfavoráveis a respeito da publicação da "Lista" e mais e mais episódios seriam trazidos à sua atenção pelas partes interessadas". ${ }^{19}$ A vigilância do Brasil poderia render-lhe um certo poder de veto, e se os Estados Unidos pretendiam evitar a acusação de violação do princípio da consulta recíproca, teriam que contemporizar, pressionando ou persuadindo setores privados ou o governo, a fim de granjear poder. Um relativo equilíbrio de forças desembocaria em negociações caso a caso.

\footnotetext{
15 Caffery 1.1.1942.

16 Simmons 21.3.1942.

17 Donnelly 21.11.1941 e 28.11.1941.

18 Aranha 15.8.1941.

19 Caffery 25.8.1941.
} 
Em Belém, a PL incitara os principais comerciantes da cidade, todos com antigas ligaçôes com os bloqueados, a procurar o cônsul, "ansiosos de se assegurar de que não seriam incluídos", alguns prometendo cortar inteiramente seus vínculos comerciais com os indicados. ${ }^{20}$ "Problemas irritantes" advindos da aplicação da "Lista" ao comércio local eram previsíveis e os cônsules e recomendavam tato e critério. ${ }^{21}$ Processos legais começavam a surgir, como a acusação de crime contra a economia nacional apresentada ao Tribunal de Segurança Nacional contra uma empresa norte-americana que se recusara a vender produtos de petróleo a um bloqueado. ${ }^{22}$ Hull pediu prudência ao comitê. Seria desafortunado para uma política que os Estados Unidos pretendiam administrar com firmeza se Aranha dificultasse futuras açôes. ${ }^{23}$ Contudo, a própria Pan American Airways discordara da aplicação da PL às suas subsidiárias latino-americanas, alegando que a recusa a levar passageiros ou cargas causaria a perda de suas franquias e criaria problemas com os governos locais. ${ }^{24}$ Pedia sua "exclusão dessa política" por comezinhas razões econômicas.

$\mathrm{O}$ comitê da PL ponderava um leque de fatores, seja para insistir ou recuar estrategicamente. Uma firma com escritórios no Rio e em Vitória foi penalizada com a inclusão na PL em agosto de 41 por recusar-se a representar a Automatic Telephones of Brazil. Alegou ser uma violação de contrato com a Siemens-Schuckert, da qual importava e com a qual resignou-se a cortar relaçóes comerciais em dezembro. Em janeiro de 42, pediu à embaixada sua exclusão da "Lista", assegurando não ter sentimentos antiamericanos. Em março, outra petição com justificativas e documentos. O cônsul em Vitória sustentou, no entanto, que os sócios eram pró-Eixo e que os britânicos tampouco viam motivos para retirá-la da SL. Em maio, a terceira carta, em julho, a quarta. Após um ano de sua inclusão, o Ministério solicitou, com documentos, sua retirada. A partir de outubro, um funcionário do Ministério, cujo cunhado era amigo de um dos sócios, passou a telefonar demandando informaçôes sobre o caso. Em novembro, as pressões chegaram a ser quase diárias. Mas o cônsul não estava convencido de qualquer "mudança de atitude", a não ser por motivos econômicos. Em novembro, um dos proprietários procurou o cônsul e falou de sua posição humilhante de membro da Lista Negra. Além de economicamente penoso, o processo era moralmente mortificante e provocava uma avalanche de súplicas, não sendo sequer vislumbrados os meios de defesa. $\mathrm{O}$ comitê se perguntava o que era mais compensador: recusar à firma a chance de reabilitar seus negócios dado o receio de que os Estados Unidos parecessem

\footnotetext{
20 Hart 8.9.1941.

21 Hubner II 31.10.1941.

22 American Embassy 29.9.1941.

23 Hull 3.10.1941.

${ }^{24}$ Department of State 8.10.1941.
} 
débeis, ou arriscar-se a perder o indispensável apoio de um governo aliado? Advertiu que o inimigo real não era a empresa, nem a PL um tapete mágico para eliminar os elementos do Eixo no Brasil. ${ }^{25}$ Quando apostou na colaboração de Vargas e aliviou a mão, para os sócios o desastre já estava consumado.

Nem os esperneios parariam por aí, nem a "Lista" deixaria de engordar. Tudo indicava que o processo seria penoso. O complexo jogo de forças se prolongaria por toda a vigência dessa política já que, na conjuntura da guerra, a economia dos Estados Unidos tendia a robustecer sua presença no Brasil, e a brasileira a tornar-se mais diversificada e dependente. À medida que surgiam obstáculos, o Departamento de Estado adotava posições defensivas. Caffery sugerira alertar os exportadores estadunidenses sobre suas responsabilidades, aliviando o constrangimento sobre os órgãos oficiais. ${ }^{26}$ A Aranha, Hull esclareceu que seu governo não entendia que a PL representasse uma interferência nos assuntos domésticos das repúblicas americanas, e dispunha-se a considerar as recomendaçôes brasileiras. Segundo ele, empresas norte-americanas sujeitas à legislação tinham admitido que suas ligaçôes com interesses inimigos tinham adquirido a conotação de atividades contrárias à solidariedade interamericana. Ao embaixador, Hull confessava-se preocupado e procurava inteirar-se dos aspectos aos quais o ministro fazia objeçōes. ${ }^{27}$ De fato, Aranha questionara a aplicação unilateral da PL durante a neutralidade do Brasil, e via as restriçóes como uma intervenção disfarçada na economia dos países neutros, que teriam a prerrogativa, por princípio, de comerciar com ambos os beligerantes. À proporção que os argumentos voltaram-se à segurança e ao interesse solidário pan-americano, viu-se forçado a aceitar as "Listas" como ação preventiva, nos casos de agressão ou da existência de suspeitas fundamentadas de sua iminente preparação. Mas por que excetuar desse acordo as medidas "que se referem às "Listas Negras", que têm repercussões comerciais nos países interessados e que causam, de ordinário, graves prejuízos a seus nacionais?" 28 A seu ver, os Estados Unidos perpetravam uma ingerência indevida ao exigir às empresas que exibissem "livros, documentos e outras provas de sua atividade comercial". Em algum momento, o Brasil haveria de transigir.

Empresas com forte apoio interno constituíam episódios embaraçosos, e a embaixada tentava evitar desgastes, nem sempre solucionados com sua exclusão da "Lista". Uma destas, tradicional do ramo óptico, ao ser bloqueada, dispensou técnicos e deixou de comprar produtos alemães. Ela era "considerada simpaticamente não somente pelo Foreign Office, mas também por funcionários amistosos do Banco do Brasil. A embaixada estaria inclinada a fazer concessões,

\footnotetext{
25 Simmons 21.11.1942-a.

26 Caffery 17.10.1941.

27 Hull 25.10.1941, Hull 21.12.1941.

28 Aranha 12.12.1941.
} 
mais do que a se afastar de elementos influentes no governo brasileiro que acreditam que nossa atitude em relação à companhia tem sido muito estrita". ${ }^{29}$ Contudo, a parcialidade resultante de pressões podia ser um precedente, afastando as autoridades amistosas nas ocorrências não-negociáveis. Portanto, havia que condescender: "a PL não é dirigida contra firmas ou indivíduos no Brasil, exceto os que são total ou parcialmente controlados pelo Eixo ou considerados inimigos do bem-estar do Hemisfério Ocidental. Firmas predominantemente do Eixo serão mantidas" e, onde existissem interesses brasileiros, anunciava-se uma revisão "com simpatia para tentar chegar a um entendimento para sua imediata remoção da PL". ${ }^{30}$ Mas, apesar de achar preferível fazer ajustes a permitir que a "Lista" se interpusesse entre os dois governos, o secretário de Estado temia já estar muito próximo o limite das concessões.

Houve conflitos entre os cinco órgãos do governo norte-americano e resultados positivos, como o fim da profusão de listas secretas, que quase paralisou os empresários, incapazes de articular as informações. A unanimidade a ser alcançada pelo comitê em cada caso, apoiada em dados ou em motivos, manteria a autoridade da PL, preveniria listas suplementares e sustentaria padrões uniformes. Tais considerações sobre legitimidade e lembravam que o Departamento de Estado não era um agente livre nesse controle, e que procurara assegurar, "mas não sem luta, a responsabilidade administrativa primária pela preparação da Lista". Isso dependia "do funcionamento contínuo e harmonioso do mecanismo" e de sua habilidade em manter firme a política da PL. A autoridade interdepartamental protegia "contra as pressões políticas que podem ter como resultado seja emascular a "Lista" seja prejudicar seriamente, em outros assuntos diplomáticos, a eficácia do Departamento de Estado,"31 o qual, responsável direto pela implementação da política externa, precisava protegerse de crises nas relações interamericanas, que mal arranhariam a reputação de outros órgãos. Reconhecia-se a necessidade de considerar casos excepcionais, desde que mantido esse caráter, já que no Brasil era difícil um acordo sereno sobre acréscimos.

Instrumento da maior importância na definição do mercado, na consolidação de posições e distribuição de oportunidades de lucros na economia de guerra, a "Lista" era objeto de uma luta encarniçada. A estratégia de garantir a autonomia do comitê por meio da referência a um pool de agências e manter secretos procedimentos consultivos diluía o ônus das deliberaçóes e deixava o ministério, que efetivamente tinha pouca capacidade de decisão, menos vulnerável a pedidos de intercessão. $\mathrm{O}$ comitê não devia abrir mão de seu poder sob qualquer circunstância, mas levaria em conta, por razões políticas,

\footnotetext{
29 Simmons 26.3.1942.

301.4 .1942$.

31 Acheson 30.3.1942.
} 
pontos de vista das autoridades brasileiras, a cujo arbítrio não pretendia deixar a "Lista" por acreditar que só objetariam à inclusão de empresas ou pessoas sem influência. O governo Vargas, que lutava para controlar intervenções na economia, incumbia-se das empresas "recuperáveis", enquanto a embaixada cuidava delas com a "mão do gato". Tal missão podia oferecer migalhas de poder a setores que, eventualmente, repartiam parte do botim entre os seus correligionários: ações, cargos ou empresas sob risco de falência por falta de acesso ao mercado norte-americano. Algumas vezes o comitê teve que capitular, deixando escapar os peixes maiores. $\mathrm{O}$ desenrolar dos processos da Cervejaria Brahma, da Melhoramentos e da Fábrica Werner mostra esses diferentes cursos.

Dentre os motivos da inclusão da Brahma na PL estava a origem germânica de boa parte de seus sócios, que teriam "tendências pró-Nazi" ou se declarado pró-germânicos, ou eram membros do Clube Alemão, "um centro de atividade nazista"; assim como o empréstimo obtido no Banco Alemão Transatlântico para a compra da Hanseática, e das Cervejarias Morávia e Atlântica. ${ }^{32}$ As reações repercutiram no Departamento de Estado, que cobrou um relatório minucioso e indagou da posição dos britânicos. ${ }^{33}$ Era um caso para negociação. A retirada dependia da assinatura do compromisso que submetia os recursos financeiros da Brahma a rígida supervisão, bloqueava seus negócios com empresas dos países inimigos e o pagamento de dividendos ou de acionistas nascidos nesses países ou bloqueados, e a obrigava a demitir empregados perigosos para a segurança do continente. Dificultava-se sua ação no mercado internacional. Para comprar tampinhas metálicas e combustível dos Estados Unidos e fazer seguro, necessitava de licenças, "pendentes da garantia definitiva de que pretende aceitar as propostas que a embaixada fez", e da demonstração de seu comprometimento. ${ }^{34} \mathrm{~A}$ Brahma não era reputada cooperativa nem um contato comercial desejável. A existência de centenas de acionistas, muitos dos quais brasileiros, tornava a negociação complexa. Quando se dava um relativo recuo do comitê, incapaz de forçá-la a dispensar funcionários, a Brahma, apoiada pelo governo, não cedia. $\mathrm{O}$ comitê montara,

em consulta com o Ministério de Relações Exteriores, um método satisfatório de controle das atividades da companhia, e vários dos empregados mais indesejáveis foram demitidos. Desde esse momento, a embaixada tem seguido o caso da Brahma de perto com o objetivo de forçar os termos do acordo em que a companhia entrou com a embaixada. Com a liquidação do Banco Alemão Transatlântico, todo o capital da Brahma pertencente a este banco ou em depósito na conta de interesses inimigos foi tomado pelo governo brasileiro. $^{35}$

\footnotetext{
323.5 .1941$.

33 Duggan 19.11.1941; Hull 30.12.1941.

34 Caffery 5.1.1942, 5.12.1941.

35 Procurement 1943.
} 
O acordo motivado por "boas razões políticas" que permitiu sua exclusão nunca foi digerido pela embaixada, que continuou a apontar como nazista, entre outros, seu diretor geral. ${ }^{36} \mathrm{O}$ caso motivou mudanças na política da PL, e passou-se a determinar em que ocasião se podia negociar, quanto e como ceder de modo a não provocar constrangimentos ou reduzir o poder dos donos da "Lista". A circular de 28.1.1942, "um dos pronunciamentos fundamentais do Departamento de Estado sobre a política da PL", contém procedimentos para lidar com autoridades nacionais em momentos de forte pressão contrária. ${ }^{37}$

A Melhoramentos, "a mais importante manufatura e importadora de madeira e de mercadorias afins do Brasil, e também a maior imprensa, litografia e editora de livros e encadernação do país", ${ }^{38}$ também comoveu o governo, que veio em seu socorro. $\mathrm{O}$ cônsul, prevendo repercussões, recomendara-a para a Black List. Contavam a seu favor dois sacrifícios: importar polpa de madeira canadense quando a suíça era mais barata e ser fiel ao carvão inglês, concorrente do alemão. Mas era membro da Câmara Alemã de Comércio; parecia colaborar com autoridades consulares alemãs; a filha de um dos sócios era enfermeira da Cruz Vermelha alemã; um de seus grandes acionistas, Alfredo Weiszflog, era simpatizante dos nazistas; outro, Walter Weiszflog, o diretor técnico e o gerente eram francamente nazistas; e 54 de suas ações pertenciam ao Banco Alemão. Para o comitê,

praticamente cada homem de importância na organização é alemão, e o idioma alemão era universal nas áreas mais altas de sua organização e funcionários. É claro que o grande número de membros, assistentes e mesmo o proprietário podem ser nascidos no Brasil, mas seus laços com a Alemanha são mais fortes, e até o arranjo dos móveis e quadros montados nas casas particulares eram completamente alemães. ${ }^{39}$

O interventor do Estado pediu a intercessão de Aranha, lembrando-lhe os 3.500 operários e suas famílias que ficariam desamparados, e que "seu diretorpresidente é brasileiro nato, e a diretoria é composta de elementos estrangeiros há muito tempo radicados no Brasil, casados com mulheres brasileiras e tendo filhos brasileiros" ${ }^{40}$ o que já os tornava brasileiros o bastante. A embaixada aceitou os argumentos, conquanto a aprovação de Hull ainda tardasse.

O terceiro episódio é o de Hilmar Werner, 75 anos, fundador em 1904 da Fábrica de Tecidos que, bloqueado em 42, propôs passar o controle da empresa ao genro, "brasileiro de descendência canadense, muito conhecido na

36 Cross 18.2.1943.

37 Donnelly 14.3.1943.

38 Simmons 17.4.1942.

39 Melhoramentos 1942

40 Aranha 21.10.1941. 
embaixada, confiável e pró-aliado". Este propôs um acordo para evitar o bloqueio da fábrica, dizendo não ter qualquer contato com o sogro, com cujas simpatias políticas "não só ele, mas sua esposa está em total desacordo". ${ }^{41} \mathrm{~A}$ embaixada fez a proposta padrão: depósito de lucros numa conta bloqueada, dispensa de empregados indesejáveis, saída de Werner da companhia, e exclusão da filha "casada com um alemão (gerente), preso por suspeita de atividades pró-Eixo". O impasse nas negociações levou a fábrica à PL em junho de 43, e logo à SL. Em menos de cinco meses, um cidadão politicamente satisfatório, amigo de Aranha e disposto a adquirir o controle acionário da fábrica procurou o comitê. ${ }^{42}$ Foi encaminhado ao Banco do Brasil, onde comprou 7.600 das 10 mil açôes e, "devido à insistência da embaixada", 2 mil adicionais. ${ }^{43}$ Entre os novos acionistas, um era concessionário da Loteria Federal, outro ligado a Luiz Aranha, irmão do ministro e conhecido na embaixada, e o terceiro, amigo do interventor federal do Rio Janeiro e genro de Vargas. A ingerência levara uma empresa conceituada a passar, da noite para o dia, às mãos de interventores e de novos proprietários, não casualmente associados a membros do governo. Com a mesma rapidez, seu fundador era jogado ao ostracismo. Vendo a questão com o afastamento que o tempo permite, a qualificação de "inimigos" justificava a prática de todo tipo de ação contra suspeitos e a transferência de vantagens para os aliados. Eventualmente reconheceram-se injustiças, como um caso em que o cônsul de Fortaleza, com base em copiosa informação adversa, havia reportado e confirmado os vínculos de uma empresa e de seu proprietário com a Alemanha, a cultura alemã e o partido nazista. Aprovou-se a inclusão. Reverteu-a o embaixador, convencido de que o proprietário tinha sido vítima de inimigos pessoais na comunidade comercial. ${ }^{44}$

A nomeação de interventores do governo às vezes resultava de pedido expresso da embaixada. Eles podiam sugerir e demitir empregados, agentes e representantes, controlar a compra e venda de mercadoria, impostos, pagamentos de salários, bônus, dividendos e contas controladas. Indicados pelo Banco do Brasil, sua qualificação era geralmente alta, mas o comitê cobravalhes eficiência e firmeza a fim de relaxar seus próprios controles. Havia também situações paradoxais como a de firmas sob intervenção, excluídas dos negócios privados, negociarem livremente com os governos estaduais. ${ }^{45}$ Empresas agraciadas com o título de "recuperáveis" precisavam cumprir exigências para merecê-lo. Assinavam compromissos de não se engajar financeira, comercialmente ou com a publicidade de pessoas e estabelecimentos da PL;

\footnotetext{
41 Caffery 11.11.1942.

42 Caffery 30.10.1943.

43 Simmons 10.1.1944.

44 Caffery 18.12.1942.

45 Braddock 10.12.1942.
} 
não agir em nome daqueles ou de interesses do Eixo; exonerar empregados indesejáveis e, "a qualquer momento que for solicitado pela embaixada norteamericana ou legação, entregar o livro da firma, relatórios, contas e correspondência examinadas por auditores aceitáveis para a embaixada ou legação, sendo tal exame feito às custas do abaixo assinado". ${ }^{46}$ A dureza do controle provocou a resistência de Vargas, a quem os estadunidenses tratavam de convencer de que a PL era condição sine qua non para que a economia brasileira importasse insumos, não menos essenciais do que os materiais estratégicos que o Brasil fornecia, e que se converteriam "em aviōes, tanques, armas e navios" e precisavam ser barateados. Os Estados Unidos estavam, "conseqüentemente, ativamente engajados não apenas na compra destes materiais, mas, ao mesmo tempo, em ajudar o Brasil financeira e tecnicamente na melhora de sua produção e processamento primário. O Brasil está cooperando maravilhosamente nesse esforço", e os brasileiros "justamente orgulhosos de cumprir e contribuir para a causa aliada". O que faltava era só um pouco de entusiasmo para que esses recursos acelerassem a vitória. ${ }^{47}$

O comitê alegava que os sacrifícios de consumo do povo norte-americano só se justificariam se houvesse "garantias razoáveis de que os produtos vão somente para pessoas e firmas conhecidas como amistosas à defesa do hemisfério e a nossos objetivos". Qualquer tentativa de debilitar a PL devia ser repelida para evitar que "exportações severamente limitadas estejam disponíveis indiscriminadamente para nossos amigos e para elementos pró-Eixo". Se Vargas não aceitasse uma PL poderosa e centralizada, esperava-se contar ao menos com sua tolerância. Mas em Washington criticava-se o Departamento de Estado e a embaixada já que, "com exceção do Brasil, todos os países americanos que romperam relações com os países do Eixo estão cooperando com os Estados Unidos na PL ou a adotaram", 48 e se acusava Vargas de falta de vontade política de colaborar. A situação escorregadia era indício da luta pelo domínio da "Lista". Para reforçar as acusações de dúbio comprometimento e de indiferença à sua política e ideais, os estadunidenses denunciaram órgãos da imprensa que aceitavam anúncios de pessoas e estabelecimentos bloqueados, e instaram suas empresas a não anunciar em tais jornais e emissoras de rádio, cortando seu acesso a suprimentos de papel e de tubos de rádio, "duas armas muito importantes já em nossas mãos" contra as ofensas. ${ }^{49}$ Contudo, empresas bloqueadas provocavam, prometendo continuar a fazer negócios como sempre. ${ }^{50}$

O comitê cobrava a demissão dos "indesejáveis", proibida pelo direito à

46 Department of State 11.4.1942.

47 McAshan, Jr. 5.11.1942.

48 Donnelly 4.1942.

49 Simmons 21.11.1942-b.

50 Hoover Jr. 7.10.1942. 
estabilidade ou onerosa devido às indenizaçôes por tempo de trabalho. $\mathrm{O}$ impacto da perda de trabalhadores capacitados e experientes repercutiria na produtividade. Restava mantê-los ociosos e remunerados. Enquanto se estudavam alternativas e alterações na lei, crescia o mal-estar com dispensas sumárias praticadas em São Paulo por empresas estadunidenses. Cerca de duzentos demitidos em busca de apoio oficial às suas demandas, muitos sem laços com sua terra natal, conquistavam a simpatia pública e criavam uma contraproducente agitação antiamericana. O cônsul urgia mudanças, enquanto os empresários procuravam meios de evitar os custos dessa política. ${ }^{51} \mathrm{Em}$ busca da colaboração de suas lideranças, de dividir o ônus do controle e reforçar os elos mútuos, a embaixada convocou-os. Reiterou que se livrassem dos empregados "inimigos", apesar dos gastos. Para atender à urgência de braços no comitê da "Lista" e no controle das exportações, funcionários recém-chegados de Washington não seriam úteis. Buscavam-se "jovens norte-americanos ativos, com experiência local e conhecimento de português". A sangria seria feita nas empresas, que assim cooperavam no esforço de guerra, cedendo seus executivos em tempo parcial. Por fim, solicitava-se qualquer informação sobre suspeitos, mesmo que parecesse trivial. ${ }^{52}$

O comitê ansiava pela modificação da legislação que impedia as demissões. Um decreto-lei autorizou, em agosto de 42, a dispensa sem indenização de oriundos do Eixo não-naturalizados, mesmo com mais de dez anos de serviço, se comprovado, por evidências ou pela polícia, serem perigosos à segurança nacional ou ao funcionamento da empresa. Quando as rescisóes de contratos começaram a ser publicadas, os norte-americanos perceberam que os mais drasticamente atingidos eram os de sobrenomes alemães. ${ }^{53}$ Eram empregados de grandes importadoras e empresas de tecnologia de ponta, cujo capital ou proprietários tinham vínculos com a Alemanha, nas posições mais altas, de confiança, ou que exigiam escolaridade: gerentes, pilotos, mecânicos e técnicos. Embora houvesse assentamentos agrícolas, boa parte dos alemães tinha ofícios urbanos qualificados.

\section{Acomodando as diferenças}

O embaixador no Rio procurava sensibilizar o Departamento de Estado da necessidade de compensar os esforços realizados pelo governo brasileiro, argumentando que este acatara um "número extraordinariamente grande de pedidos que fizemos de privilégios extraordinários relativos à defesa do hemisfério". Materiais estratégicos em quantidade e "a preços muito mais baixos

\footnotetext{
51 Hull 17.12.1941 e Cross 22.12.1941.

52 JFS 9.12.1941.

53 Donnelly 15.12.1942.
} 
do que os exorbitantes pagos então pelo Eixo" eram a contrapartida a se "continuar a facilitar o embarque de materiais essenciais à indústria brasileira". Contava-se com cooperação em tarefas como detectar espiōes, mas notava-se em Vargas e em Aranha, amáveis em outros assuntos, um permanente descontentamento em relação à PL. O sentimento de o país ser tratado como uma banana republic contribuía para a reação, já que "eles são perfeitamente capazes de cuidar à sua maneira de seus interesses econômicos e, por outro lado, dos elementos do Eixo em seu meio. Eles se ressentem do que chamam de nossos métodos imperialistas" ${ }^{54}$ A retaliação podia resultar na expulsão do espaço aéreo brasileiro do Ferry Command que conectava Natal a Dacar pelo caminho mais curto e seguro no momento. A expectativa do embaixador parecia não ser das melhores, tanto que prometia para breve uma carta mais construtiva. Num pós-escrito, acrescenta o desabafo que lhe fizera Aranha, depois de instruir o enviado brasileiro a Washington: "agora eu acredito que vocês vão nos deixar em paz com essa questão da PL". Nesse quadro, o FBI, em documento com possíveis finalidades propagandísticas, considerou o Brasil o "o mais importante país sul-americano no que diz respeito ao programa de guerra dos Estados Unidos. Ele não é superado por nenhum outro no mundo em recursos naturais, na maior parte não explorados". ${ }^{55}$

Num balanço sobre a "Lista", considera-se que não houve resultados "satisfatórios" imediatos, mas em pouco mais de um ano exibiam-se estatísticas animadoras:

foram feitas, aproximadamente, 7.500 histórias e 2.300 fichas de caso individuais, e estão em uso 106 arquivos gerais de trabalho. A seção da PL recebe em média cerca de 50 chamadas telefônicas e mantém de 20 a 25 chamadas pessoais por dia [e] continha 265 nomes quando foi publicada pela primeira vez. Desde então houve 66 exclusões. A lista total inclui agora aproximadamente 675 nomes. ${ }^{56}$

Mas a interrupção dos acréscimos, o adiamento de objetivos da PL e mesmo a exclusão de certas empresas, ocorridos em função da realização da Conferência do Rio, foram avaliados como um recuo. Autoridades brasileiras tinham imposto a discussão de ocorrências individuais, colocando em pé de igualdade acusações com e sem fundamento e, mesmo quando ofereciam cooperação, de fato estavam "protegendo alguns dos mais poderosos interesses nazis" que, fortalecidos, resistiam melhor às tentativas subseqüentes. Aranha mantivera na "Lista", vários meses depois de decidida sua retirada, uma empresa com a qual desejava lidar "como um instrumento de política interna". Essa

\footnotetext{
54 Caffery 14.4.1942.

55 FBI 21.3.1942.

5611.1942.
} 
flexibilização desmoralizava a PL, especialmente em casos importantes sobre os quais o público estava informado. Difundia-se uma impressão de que a embaixada agia "punitivamente contra ofensores não importantes, mas fazia vista grossa para as grandes casas comerciais". ${ }^{57}$ Se elementos significativos do Eixo não fossem duramente golpeados, a política seria ineficaz "e nos faria parecer ridículos".

Em São Paulo, a PL está sendo ridicularizada e o governo dos Estados Unidos está perdendo muitos amigos devido às atuais condiçôes. Em Manaus, um distrito no qual pretendemos investir milhôes de dólares, a organização comercial do Eixo está ao menos tão forte quanto antes da publicação da PL. Em Santos, o mercado do café desconsiderou abertamente a PL, mesmo em benefício dos japoneses, e é duvidoso se teremos força bastante para recuperar o prestígio que perdemos. Em outras partes do Brasil o resultado não tem sido tão desafortunado simplesmente porque a "Lista" não os afeta diretamente..$^{58}$

Talvez em função de frustrações, houve golpes desproporcionais, como o sofrido pela Cappuccini \& Cia., pequena e bem reputada importadora de tintas composta de marido e mulher italianos, residentes no Brasil há 33 e 24 anos respectivamente, "bem vistos e competentes, bons pagadores, bons para créditos moderados", com referências de bancos italianos e alemães e da Câmara de Comércio Italiana. Em maio de 40, acusada de receber produtos alemães via New York, entrou para a SL, e em julho para a PL. Desde então não houve outras evidências. Somente em novembro de 43, a empresa enviou pedidos de exclusão aos britânicos e aos norte-americanos. Estes consideraram incomuns as razões da demora: seus profundos sentimentos religiosos, a pequena importância da firma, a probabilidade de que seu chefe, com a saúde minada, morresse em breve, e porque não esperava uma rápida solução para o conflito em vista do poder da frota britânica. No mês seguinte, o comitê da PL considerou enviar, "no devido momento", recomendação para a retirada da empresa e de seus sócios, já que, desde a queda de Mussolini, observara mudanças de atitude. ${ }^{59}$ Contudo, dentre as novas condições para a exclusão de empresas italianas, uma impedia retirar "firma ou pessoa italiana que tenha sido predominantemente e ativamente identificada com a organização fascista local e tenha se engajado em atividades ou em propaganda políticas destinadas a auxiliar o Eixo", e o proprietário teria sido vinculado às principais organizaçóes fascistas no Brasil. O comitê devia avaliar a repercussão, sobre a comunidade local e italianos antifascistas, da exclusão de firmas ou indivíduos italianos e nacionais pró-Eixo a fim de não difundir a impressão de relaxamento dos

\footnotetext{
57 Cunningham 29.7.1942.

58 Cunningham 29.7.1942.

5914.12 .1943$.
} 
critérios, e identificar quem se empenhava em demonstrar mudança em suas convicções políticas e uma recém-assumida fidelidade às Nações Unidas. ${ }^{60}$ $\mathrm{O}$ assunto Cappuccini se arrastava. Em fevereiro de 44 ainda era discutido, apesar de os britânicos terem abrandado sua posição. ${ }^{61}$ Assinados os compromissos, a firma foi retirada da SL em agosto e, em setembro, da PL. De fato, muito barulho por nada. Uma empresa economicamente insignificante sofrera uma punição de mais de três anos da qual as grandes escapavam graças à interferência do governo.

Em 43 o Departamento de Estado julgou que a PL atingira um significativo sucesso: o Banco do Brasil restringira créditos a nacionais bloqueados e pretendia usá-la "como parte da administração do controle de exportações"; "uma organização puramente financeira, sem nenhuma conexão com os Estados Unidos, três semanas depois de ter sido incluída na PL, estava à beira da bancarrota"; havia mais aceitação nos setores de comércio e finanças; aumentara a eficiência da inteligência, e "fontes valiosas de informação foram estabelecidas, em muitos casos dentro do governo. Como resultado, a embaixada era, no momento, a organização mais bem informada no Brasil sobre questôes de inteligência comercial, sendo regularmente consultada pelas autoridades brasileiras em questôes deste tipo". Comemoravam-se os resultados arrasadores da política de guerra econômica. Decretos-leis haviam passado empresas importantes a outros proprietários, acionistas e gerentes.

$\mathrm{Na}$ área norte do Rio de Janeiro e em Minas Gerais, interesses inimigos têm sido virtualmente eliminados, com exceção de uma grande fábrica de charutos na Bahia e uma pequena fábrica de chocolates em Vitória. Os interesses inimigos, que anteriormente dominavam a vida comercial no vale do Amazonas, desde a fronteira boliviana até Belém, podem ser ditos liquidados. No Ceará, em Pernambuco e na Bahia, os estabelecimentos comerciais estão quase inteiramente fechados. No sul do Brasil, onde interesses inimigos são mais concentrados e onde têm se desenvolvido importantes estabelecimentos industriais, o efeito da "Lista" tem sido até agora meramente de enfraquecimento de sua posição e, em alguns casos, de forçar sua transferência a novas mãos. ${ }^{62}$

O Departamento de Estado voltou-se ao programa de substituição de técnicos, informando-se sobre o número necessário, especialidades e salários oferecidos, já que haveria grande interesse do governo brasileiro em preencher as vagas com norte-americanos e acelerar os procedimentos de nacionalização. ${ }^{63}$ As vantagens em fornecê-los eram a de reduzir o pessoal do Eixo na indústria,

6016.12 .1943$.

6116.2 .1944$.

62 Procurement 1943.

63 White, Waring, Phelps 8.2.1943.

64 Tewell 15.3.1945. 
a de aumentar a produtividade, a de baixar custos da produção de medicamentos e materiais estratégicos, e a de ampliar a entrada no setor produtivo, substituindo tecnologia e processos moldados em padrōes germânicos. Mas o governo brasileiro não demitiria se não se providenciasse imediatamente pessoal qualificado para as vagas. Potenciais compradores exigiam as exonerações, apesar do "sacrifício financeiro, representado pelas indenizaçóes (...) e pelas mais altas remunerações que, sem dúvida, seriam requeridas pelos substitutos obtidos nos Estados Unidos", ${ }^{4}$ mas duvidavam do apoio de Vargas ou dos aliados contra pleitos de antigos proprietários. Em vista desses impasses, a embaixada sugeriu a inclusão, "nos tratados de paz ou acordos de armistício com as potências do Eixo, de cláusulas requerendo ao governo dos países inimigos e seus cidadãos que expressassem categoricamente" a renúncia a tais ações.

A embaixada desconfiara de liquidantes, administradores do programa de substituição e protegidos de autoridades; queixara-se da tímida demissão de suspeitos e de antigas equipes de direção; fora ignorada por apadrinhados de prestígio. Mas os "registros do inimigo" estavam à sua disposição permitindolhe adquirir "uma penetrante visão sobre o modo pelo qual estas firmas foram usadas para atividades indesejáveis" e "fizera um exame completo de arquivos e registros", como os do Banco Alemão, onde cerca de cem empresas tinham feito empréstimos, tendo sido "em muitos casos, confirmados os pontos de vista da embaixada a respeito de firmas específicas, ou fornecidas valiosas indicações para pesquisa adicional". Um relatório com os resultados "deve provar-se interessante para as autoridades em Washington”. O Brasil mostrava "uma tendência" a responder favoravelmente à embaixada que, exonerada de tarefas periféricas, aperfeiçoava as de inteligência e investigava conexões entre informaçōes a fim de traçar um quadro da rede internacional de relações das empresas mais importantes, consolidando e estendendo o poder econômico e político estadunidense.

\section{Conclusões}

Uma das conseqüências mais duradouras e funcionais do processo desatado pela implementação da PL foi a racionalização da máquina de Estado norteamericana: novas agências, emergenciais e permanentes, aparelhamento das representações diplomáticas, articulação entre o serviço exterior e o de inteligência, ampliação do papel do Departamento de Estado. Especialistas e equipes mistas dos setores público e privado colheram e analisaram informações, definiram objetivos, prazos e meios para implementar, com agilidade, políticas adequadas às condições locais e, assim, otimizar ações. Volumosos e complexos relatórios sobre temas econômicos, sociais, culturais e políticos evidenciam o 
profissionalismo dos órgãos responsáveis pela política externa.

Conflitos limitaram a margem de manobra, obrigando à renúncia de objetivos e à partilha de ganhos com aliados locais. No Estado brasileiro, palco também de profundas transformaçōes, disputou-se o controle do mercado para aproveitar a instável conjuntura. Em situação desvantajosa, proprietários e empregados associados a países do Eixo tentaram salvar a própria pele. $\mathrm{O}$ resultado foi no mínimo paradoxal, uma vez que firmou, ao mesmo tempo, a base econômica do nacionalismo brasileiro e a dependência do país em relação ao capitalismo norte-americano. $\mathrm{O}$ movimento pendular da política do Brasil em relação aos Estados Unidos foi resultado da difícil tarefa de conjugar, nas circunstâncias da guerra, autonomia e desenvolvimento, cabendo à figura de Vargas, na historiografia nacional, encarnar a ambivalência desse processo.

Recebido em 4 de maio de 2006 Aprovado em 15 de setembro de 2006

\section{Fontes primárias}

Record Group 226, Office of Strategic Services: FBI. 21.3.1942. Microfilm.

Record Group 59, Central Files 1940-44:WHITE; WARING; PHELPS. 8.2.1943.

Record Group 84:

AMERICAN EMBASSY. 16.12.1942.

ARANHA. 15.8.1941, v. XX.

ARANHA. 21.10.1941, v. XX.

CAFFERY. 25.8.1941, v. XX.

HART. 8.9.1941, v. XXI.

HUBNER II. 31.10.1941, v. XXI.

HULL. 25.10.1941, v. XX.

MCASHAN Jr. 5.11.1942, v. XI.

Record Group 84, Confidential Files:

11-1942, v. IV-EC.

1.4.1942, v. IV-EC.

ACHESON. 25.11.1941, v. II A-EC.

ACHESON. 30.3.1942, v. VI-EC.

AMERICAN EMBASSY. 29.9.1941, v. II A-EC.

ARANHA. 12.12.1941, v. II B-EC.

BRADDOCK. 10.12.1942, v. VI-EC.

BRITISH EMBASSY. 11.8.1941, v. II A-EC. 
CAFFERY. 14.4.1942, v. V-EC.

CAFFERY. 17.10.1941, v. II A-EC.

CAFFERY. 24.12.1941, v. II B-EC.

CAFFERY. 26.11.1941, v. II A-EC.

CROSS. 18.2.1943, v. II B-EC.

CROSS. 22.12.1941, v. II B-EC.

CUNNINGHAM. 29.7.1942, v. V-EC.

DEPARTMENT of STATE. 11.4.1942, v. IV-EC.

DEPARTMENT of STATE. 7.12.1942, v. VI-EC.

DEPARTMENT of STATE. 7.2.1941, v. II A-EC.

DEPARTMENT of STATE. 8.10.1941, v. II A-EC.

DONNELLY. 13.11.1942, v. VI-EC.

DONNELLY. 15.12.1942, v. IV-EC.

DONNELLY. 21.11.1941, v. II A-EC.

DONNELLY. 28.11.1941, v. II A-EC.

DONNELLY. 4-1942, v. V-EC.

HULL. 17.12.1941, v. II A-EC.

HULL. 21.12.1941, v. II B-EC.

HULL. 30.12.1941, v. II B-EC.

HULL. 3.10.1941, v. II A-EC.

JFS. 9.12.1941, v. II B-EC.

SIMMONS. 21.11.1942-a, v. IV-EC.

SIMMONS. 21.11.1942-b, v. VI-EC.

SIMMONS. 21.3.1942, v. IV-EC.

SIMMONS. 26.3.1942, v. IV-EC.

Record Group 84, Strictly Confidential Files: Procurement of Strategic Materials 1943.

WIF, Records of Proclaimed List:

14-12.1943.

16.12 .1943 .

16.2.1944.

Melhoramentos 1942.

3.5.1941.

5.12.1941.

CAFFERY. 11.11.1942.

CAFFERY. 1.1.1942.

CAFFERY. 1.4.1942.

CAFFERY. 18.12.1942. 
CAFFERY. 30.10.1943.

CAFFERY. 5.1.1942.

DONNELLY. 14.3.1943.

DUGGAN. 19.11.1941.

HOOVER, Jr. 7.10.1942.

SIMMONS. 10.1.1944.

SIMMONS. 17.4.1942.

TEWELL. 30.11.1943.

TEWELL. 15.3.1945. In: UNITED STATES. Foreign Relations of the U. S. 1945. Washington: Government Printing Office, v. IX, p. 650-9.

\section{Documento eletrônico}

http://www.ushmm.org/uia-cgi/uia_doc/art/x10-37?hr=null (Disponibilidade: 27/4/2005).

\section{Resumo}

No artigo são analisados os conflitos políticos gerados pela implementação das "Listas Negras" norte-americanas entre órgãos estatais e interesses privados no Brasil durante a Segunda Guerra Mundial.

\section{Abstract}

The article analyses the political conflicts caused by the implementation of American Black Lists between State agencies and private interests in Brazil during World War II.

Palavras-chave: "Listas Negras", Brasil, Estados Unidos, política externa interamericana, Segunda Guerra.

Key words: Black Lists, Brazil, United States, Inter-American foreign policy, World War II. 